\title{
Antoinette Schapper* \\ Baring the bones: the lexico-semantic association of bone with strength in Melanesia and the study of colexification
}

\author{
https://doi.org/10.1515/lingty-2021-2082
}

Received March 22, 2021; accepted March 3, 2021; published online July 27, 2021

\begin{abstract}
In this article I demonstrate that there is a pervasive lexico-semantic association BONES ARE STRENGTH in the languages of Melanesia, but that its linguistic expression is highly varied; languages are scattered along a lexical-to-clausal cline in their expression of the association between bone and strength, with a large number of language-specific idioms based on the association to be observed in Melanesia. I argue that the striking areality of this lexico-semantic association is readily missed in top-down approaches to lexical semantic typology that rely, for instance, on databases of word lists, or on narrow search domains limited to the meanings of simplex lexemes.
\end{abstract}

Keywords: colexification; comparability of languages; Melanesian linguistic area

\section{Introduction}

Over the last 60 years or more, typologists have made great strides in understanding the diversity and uniformity of the world's languages. For many variables within the

\begin{abstract}
This paper was written up under the auspices of a Brill Fellowship at the Scalinger Institute of the Leiden University Library. Research funding came from the Netherlands Organisation for Scientific Research VENI project "The evolution of the lexicon. Explorations in lexical stability, semantic shift and borrowing in a Papuan language family", the Volkswagen Stiftung DoBeS project "Aru languages documentation", the INALCO-funded projet scientifique blanc "Merging meanings in Melanesia", the Australian Research Council project (ARC, DP180100893) "Waves of words", and the European Research Council "OUTOFPAPUA" project (grant agreement no. 848532). Numerous linguists aided this study through data and discussion. I am grateful to Alexandre François, Lameen Souag and other members of the Labex group "Lexical typology across time and space" for many helpful discussions on lexical typological topics. Finally, many thanks to two anonymous reviewers and to my fellow editors, Maria Koptjevskaja-Tamm and Felix Ameka, whose critical remarks greatly improved this paper. All errors are my own.
\end{abstract}

Corresponding author: Antoinette Schapper [æn'tw^nєt 'Jæpə], Vrije Universiteit Amsterdam, Amsterdam, The Netherlands, E-mail: a.c.j.schapper@vu.nl 
domains of phonology and morpho-syntax, linguistic typology has developed an increasingly detailed picture of recurrent linguistic features, of correlations between linguistic features, and of correlations between linguistic features and non-linguistic phenomena. The typological investigation of the lexicon has, however, lagged behind the study of these other elements of linguistic structure (despite several wellknown and highly cited studies on a range of semantic fields, including Andersen 1978; Berlin and Kay 1969; Talmy 1985; Viberg 1984), both in the number of studies and the diversity of lexical phenomena treated. It is debatable whether the lack of typological research into the lexicon is due to it being regarded as merely "an appendix of the grammar, a list of basic irregularities" (Bloomfield 1933: 274), or as simply too massive and diverse, especially in comparison to the more constrained parameters of morphosyntax. However, a new wave of lexical typological research in the last 15 years has broadened the cross-linguistic study of the lexicon beyond the small number of semantic fields dealt with in earlier studies through systematic analysis of lexico-semantic associations and morphological motivations for a wide range of lexemes (e.g., Koptjevskaja-Tamm 2015; Koptjevskaja-Tamm and Vanhove 2012; Urban 2012; Vanhove 2008).

Within this recent body of research, the colexification approach established by François (2008) has gained wide currency among typologically oriented linguists. Sidestepping "the vexing problem of distinguishing between polysemy and vagueness” (Haspelmath 2003: 231), the colexification approach constructs expandable etic grids of meanings on the basis of semantic distinctions lexicalized in languages, regardless of the emic status of the meanings in any one language. Since François (2008), there have been several studies in lexical typology which make use of colexification (most notably, Urban 2012). As a methodology, it has produced robust and innovative results, not least of all in the domain of areal linguistics (e.g., Koptjevskaja-Tamm and Liljegren 2017; Schapper et al. 2016; Schapper 2017, 2019; Urban 2009, 2010, and the articles in this issue). The emergence of colexification as a new tool for lexical typological research has been concomitant with the growth of digital databases of lexical material from across the languages of the world, chiefly for the purposes of historical-comparative linguistic research (e.g., WOLD, Haspelmath and Tadmor 2009; IDS, Key and Comrie 2015; ASJP, Wichmann et al. 2018). Inevitably, these databases have been co-opted for use in colexification studies concerned with identifying patterns or skewings of patterns on a global-scale (e.g., Gast and Koptjevskaja-Tamm 2018; Jackson et al. 2019; Östling 2016; Pericliev 2015) and given rise to collated databases for automized detection of colexifications, most notably the various incarnations of CLICS (Version 1: List et al. 2014, Version 2: List et al. 2018, Version 3: Rzymski and Tresoldi 2020). In this contribution, I draw attention to the pitfalls of simplistic implementations of the colexification approach using databases based 
on naïve wordlists that require complete identity between cells for a colexification to be detected.

Colexifications are, at their broadest, lexico-semantic associations ${ }^{1}$ that can manifest themselves linguistically in different languages through different formal means, including the extensional range of a single lexeme's semantics, complex lexical items such as compound words and phrases, or larger constructions, formulae and idiomatic expressions. I address this issue here through an examination of the lexico-semantic associations of lexemes denoting 'bone' in the Melanesian Linguistic Area. Centred on the island of New Guinea, Linguistic Melanesia is defined as the area in which Papuan languages and their influences are found (Ross 2017; Schapper and de Vries 2018; Schapper 2020). It takes in upwards of 1,000 languages across 20 to 40 language families; Papuan languages from numerous unrelated families dominate at its core, but a large number of Austronesian languages are also taken in, particularly in the insular and coastal regions on and around New Guinea. ${ }^{2}$ In this article I demonstrate that there is a pervasive lexico-semantic association BONES ARE STRENGTH in the languages of Melanesia, but that its linguistic expression is highly varied; languages are scattered along a lexical-to-clausal cline in their expression of the lexico-semantic association between bone and strength, with a large number of language-specific idioms being based on the association observed in Melanesia. I argue that the striking areality of this lexico-semantic association is readily missed in top-down approaches to lexical semantic typology that rely, for instance, on databases of word lists, or on narrow search domains limited to the meanings of simplex lexemes.

The paper is structured as follows. Section 2 discusses the colexification approach and associated issues. Section 3 presents an overview of common patterns of cross-linguistic colexification for the target meaning of this article, 'bone'. Section 4 discusses the numerous lexical patterns and expressions underpinned by the lexico-semantic association BONES ARE STRENGTH in the languages of Melanesia, highlighting problems in capturing the cross-linguistic similarities in these when using a narrowly applied colexification approach. Section 5 argues for the areality of the association of bone with strength in Melanesia and suggests that the diversity of its manifestations in the languages of Melanesia fits in with the

1 Following Koptjevskaja-Tamm and Liljegren (2017), I use the term "lexico-semantic association" as a cover term for colexification, lexico-constructional parallels and shared phraseology.

2 The core of the Melanesian Linguistic Area is the island of New Guinea. Greater Melanesia takes in a large area to the east and west of New Guinea, extending from the island of Sulawesi in Indonesia to the western fringe of Polynesia and stopping just short of the islands of Fiji, Vanuatu and New Caledonia (Schapper 2020). 
well-known structural convergence-lexical divergence model for the area. Section 6 concludes.

\section{What is colexification?}

François (2008) articulates a practical method for detecting shared lexical packaging of senses across languages based on the simple concept of 'colexification': "A given language is said to colexify two functionally distinct senses if, and only if, it can associate them with the same lexical form" (François 2008: 170). Confusion about what "functionally distinct senses" are has been the basis of criticism of the colexification approach. Although generally positive about colexification as a development in lexical typology, McConvell and Ponsonnet (2013) observe that it is often impossible on empirical grounds to decide whether two meanings found in two different languages are one or two senses. However, François (2008) does not require us to distinguish; the phrase "functionally distinct senses" is intended to refer to any semantic distinction potentially lexicalized in a language, with no regard to whether the speakers of any one language view the meanings associated with a lexeme as psychologically distinct senses, contextual readings of the same sense, or accidental homophones. Stating a colexification, therefore, involves forming an etic grid on the basis of the semantic distinctions lexicalized in a sample of languages, without regards to the emic status of the meanings associated with a lexeme in any one language. For instance, Table 1 represents an etic grid of three meanings 'fire', 'firewood', and 'tree', lexified distinctly in four Papuan languages: Kalam colexifies all three meanings; Kamang colexifies 'fire' and 'firewood', but has a distinct lexeme for 'tree'; Eipomek colexifies 'firewood' and 'tree', but has a distinct lexeme for 'fire'; and, Yimas has distinct lexemes for all three (cf. Schapper et al. 2016).

Table 1: Etic grid of 'fire', 'firewood', and 'tree' in four Papuan languages.

\begin{tabular}{lllll}
\hline & Kalam & Kamang & Eipomek & Yimas \\
\hline 'fire' & mon & ati & ukwe & awt \\
'firewood' & mon & ati & yo & ampra \\
'tree' & mon & bong & yo & yan \\
\hline
\end{tabular}

Burenhult et al. (2017) implicitly criticize the colexification approach, suggesting that in practice it is little more than the comparison of translation equivalents. In their study of 'forest', they state that looking for possible translation 
equivalents for it is "a simplistic and selective approach to lexical semantics, and one that does not do justice to the complexities of language-specific lexical systems" (Burenhult et al. 2017: 456). Urban (2012: 41) counters these kinds of criticisms by pointing out that "while there is not necessarily a set of lexical items whose semantics corresponds to, say, English words such as mountain, river, etc., there are lexical items that allow [one] to refer to these configurations in the landscape, and it is not least the variation in the other semantic areas covered by the respective expressions that are [...] important."

Because colexification studies are still very much in their infancy, there is a need for a discussion and evaluation of the comparability of the lexical structures under study. I draw attention here to two particular issues, neither of which are new in the broader semantic typology literature. However, to my knowledge, they have not been raised in any significant way in the emerging colexification literature, but should be kept in mind in the development of future colexification studies.

The first issue surrounds the morphosyntactic analysis of colexifications. Two subtypes of colexification are identified by François (2008): (i) strict colexification where the exact same form in synchrony can be used for senses A and B (e.g., Kamang ati for 'fire' and 'firewood'), and (ii) loose colexification ${ }^{3}$ where there is a connection between the two either diachronically (e.g., Waskia tama 'fire' and tam 'firewood' are obviously historically related, but not by any identifiable regular, synchronic process, Malcolm Ross pers. comm.) or morphologically (e.g., Klon ada? 'fire' and adawel 'firewood', a compound of 'fire' and 'burn (intr.)'). ${ }^{4}$ In identifying loose colexifications, Urban (2012) correctly makes no distinction between compounds (e.g., noun + noun) and phrases (e.g., noun + adjective), treating both as types of modifier of the head noun. As we shall see in this paper,

3 Schapper et al. (2016) refer to the presence of colexifying elements in compounds as "subcolexification". That is, sub-colexification for them is a special kind of loose colexification which involves compounding of lexemes, as opposed to marking with grammatical morphemes. Urban (2012) uses "analysability" to characterize morphologically complex expressions formed by any language-specific syntactic or morphological process of word-formation.

4 "Loose colexification" covers much of what has been called "heterosemy", the situation in which different but related senses of a given lexeme are associated with distinct morphosyntactic contexts (Lichtenberk 1991). Note, however, that François (pers. comm.) regards "pure heterosemy" as strict colexification. For Evans and Wilkins (2000), these heterosemies are situations in which there is no morphological marking or derivation on the lexeme to distinguish different senses (e.g., Kómnzo mni with feminine agreement for 'fire' and mni with masculine agreement for 'firewood', or instances of zero conversion like hand as body part noun and hand as a verb). 
the same lexico-semantic association can manifest itself on the level of the simplex lexeme, the morphologically derived lexeme, the phrase, or even the clause. François (2008: $170 \mathrm{fn}$ 4) appears to recognize this issue in his important article, writing that senses can be shared not simply between lexemes but also constructions. I will show that identifying lexico-semantic associations on the different levels of linguistic structure is important for the detection of shared patterns in different languages and language areas.

The second issue concerns the need to attend to the contexts of a lexeme's use. These are important not simply for explaining the existence of colexifications, but also in detecting ongoing semantic extensions leading to colexifications. Evans and Wilkins (2000) observe that when a lexeme's semantics are first extended, the new meaning often comes into existence in a regular context that allows an inference of a second meaning to arise and, only given sufficient frequency, to later become lexicalized. They rightly point out that attention to these "bridging contexts" is essential: "speech participants do not detect any problem of different assignments of meaning to the form because both speaker and addressee interpretations of the utterance in context are functionally equivalent, even if the relative contributions of lexical content and pragmatic enrichment differ" (Evans and Wilkins 2000: 550). Looking for uses of target lexemes in context is particularly important for languages where linguistic documentation is relatively basic and the lexicon has not been the subject of close semantic analysis. In the course of the present study, contextualized attestations of 'bone' in many cases revealed the relevant, often repeated, lexico-semantic association of BONES ARE STRENGTH and extended senses, even though not listed as a sense of 'bone' by individual linguists or linguistic reference works. In addition, by examining the morphosyntactic contexts in which lexemes denoting 'bone' were used with a contextual association to strength in different languages, a picture of the staged emergence of the lexico-semantic association of BONES ARE STRENGTH was constructed.

\section{Colexification patterns of 'bone' worldwide}

Before turning to the Melanesian data with which we will interrogate these problems, it is useful to have a picture of world-wide variation with which to establish the areality of the linguistic phenomenon in question. The meaning 'bone' is observed by Urban (2012: 621-622) to have relatively few lexical associations crosslinguistically, compared with the other nominal meanings covered in his study. This view is largely borne out by the synchronic colexification patterns discovered 
in my own investigation as well as through an examination of the CLICS databases ${ }^{5}$ and the Database of Semantic Shifts (Zalizniak et al. 2012). Only a small number of synchronic colexifications for 'bone' are found repeatedly the world over, as will be shown in this section. ${ }^{6}$ We will see that the rarity of an association of 'bone' with strength makes it a good candidate for an areal linguistic feature.

The most common lexical associations of 'bone' are far and away contiguitydriven; colexification of 'bone' is overwhelmingly with (parts of) the body. These colexifications are found sporadically the world over and rarely, if ever, show any strong areal or genetic skewing. Specific bones of the body that colexify with 'bone' in the world's languages are 'shin' (Kartujarra, Catio, Guayabero, Central Tunebo and eight Atlantic-Congo languages: Chuka, Gwere, Kiseri, Mabia, Meruimenti, Rukiga, Sambaa and Zanaki), 'spine' (Rumanyo, Upper Chehalis, Maca, Kumyk, Takia) and relatedly 'back' (Tabriak, Lau, Walade, Vano, Flinders Island, Kalali, Mirniny), 'rib' (Tuamotuan, Alorese, Kula, Paliu, Bolewa, Mang'an B), 'shoulderblade' (Upper Chehalis, Yavitero, Avar), 'ankle' (Karata), 'collarbone' (Mlabri) and 'jaw' (Kimbu), as well as 'tooth' in Oro Waram, Mapudungun and several Madang languages (Isabi, Ogea, Siane, Uyajitaya). Colexification of 'bone' with 'leg' is synchronically attested in Kartujarra, Guayabero, Central Tunebo, Epena, Ese Ejja, Mundurukú, Lengua, Kobol, Moere, and most well-known of all, in many of the Germanic languages, while 'bone' colexifies with 'foot' in Siraya, Embera Tadó, Amto and Nagatiman. We find 'bone' and 'head' colexify in Momuna and three unrelated languages of New Guinea (Konda, Duna, Iau). Chorote, several Daghestanian languages (Andi, Archi, Avar,

5 Note that when I refer to "CLICS", I mean the first, second and third editions of CLICS collectively. While CLICS ${ }^{2}$ and CLICS $^{3}$ have expanded data sets and thus greater coverage, CLICS 1.0 allows the user to see all colexifications no matter how infrequent their attestation in the database. The interfaces in CLICS $^{2}$ and CLICS $^{3}$ set a threshold of three attestations for a colexification to be outputted by a user's query. While such a threshold might be a principled way for a researcher to draw a line between accidental homonymy and actual polysemy, for an interface to mask data in this way is extremely unfortunate. It means that using the interface developed by the CLICS team actually prevents the researcher from making connections between colexifications that are recurrent in the data, but might be glossed in slightly different ways, perhaps as an artefact of the way a wordlist was collected. A case in point is the colexification of 'bone' with 'stick' or 'branch' in different languages; clearly both reflect a biological analogy between the bone of a human/ animal and the woody parts of plant. 'Bone'/'stick' colexification is shown in CLICS ${ }^{2}$ because it has four attestations, but 'bone'/'branch' colexification is not because it only has two occurrences in the data, as reflected in CLICS 1.0.

6 The reader is referred to the appendices for further data used for this section, as well as ISO 639-3 codes. Appendix I is my database on the association of 'bone' with strength in Melanesian languages, but also includes examples of other associations of 'bone' that are common in Melanesia. Appendix II contains summaries of the data from online databases that were used. Urban's (2012: 621-622) discussion of associations 'bone' does not always include the forms of the items he discusses and so is not represented in Appendix II. 
Chamalal, Dargwa, Karata), and the Turkic languages Kumyk and Nogai colexify 'bone' with 'corpse'. Related to this is the colexification of 'bone' with 'body' in Otomi, Lengo, Longgu and Nggela, as well as the colexification of 'bone' with 'skeleton'-a concept not found in CLICS1 or CLICS2 - that is observed by Urban (2012) in Kalkha, Tusarora, Bororo, Cashinahua, Embera, Guaraní, Huambisa, Tehuelche, and Rotuman. There are two further minor patterns: Tubbe (Western Pantar) and Dera- two unrelated, spatially removed Papuan languages - colexify 'bone' and 'meat', while South Qiandong, Siawi and Usku colexify 'bone' and 'blood'.

Beyond the body, metonymy-driven colexifications are rare. Colexification with man-made implements, presumably originally made from bone, are various but sporadic: Zuni sa 'bone, plate, bowl, cup, drinking vessel, dish, pan, saucer', Budukh чанахъ 'bone, plate, bowl'; similarly, Rotuman, Wappo and Yuki colexify 'bone' and 'needle'; Tsafiqui Pila and Colorado colexify 'bone' and 'club', and; Teiwa colexifies 'bone' and 'comb'.

Colexifications with 'bone' based on biological analogies are attested widely cross-linguistically. These colexifications with 'bone' mostly refer to a homologous structure in animals and plants, and occasionally, inanimates. While most vertebrates have bones much like humans, there are other animal parts which are also treated as homologous structures, particularly in non-land animals. This is seen in the varied colexification data: 'bone' colexifies with 'horn' in Yakut, Highland Chontal and Itzaj; with 'fishbone' in Buli and Basque, but 'fishscale' in Lezgi (Mikrakh), 'projecting spike on the fins of certain fish' in Rotuman, and 'dorsal fin' in Mwotlap; with 'shell' (e.g., of a mollusc, turtle) in San Lucas Quiaviní, Qawasqar, Nama and Hawaiian, and; with 'egg' in Yangulam (as well as 'fruit'), Kwoma and Ngoreme (as well 'reed' and 'thorn' in the latter, see below).

What colexification patterns capture as homologous structures in plants are similarly diverse. 'bone' colexifies with various woody or structure-giving parts of the plant, including with 'stalk' in Ngaanyatjarra, Sora, Arabela, Lengua, Maxakali and Yanomámi, with 'branch' in Seri and Yuwana and, relatedly, with 'stick' in Secoya, Garus, and Mungkip, with 'stem' in Aghu, with 'tree trunk' in Northern Emberá, with 'tree' and 'wood' in Colorado, with 'tree' and 'stick' in Tsafiqui Pila, and with 'tree' in Qawasqar and Kalkutung. Less frequently, 'bone' colexifies with reproductive parts of the plant, typically, as contained in hard casings; most common in this type is the colexification of 'bone' with 'seed', found in 11 languages (Sinhalese, Karajá, Rumai, Bahinemo, Mende and a cluster of six Austronesian languages). Related colexifications are 'bone' with 'stone (of a fruit)' in Modern Greek, Latin, Lahu Shi, Mongolian (Khalkha), Middle Persian (Pahlavi), Khmer and Yakut and with 'hard inner shell' (e.g., of a coconut or mango) in Melanesian languages such as Bosavi, 
Mende and Kâte, to name a few. ${ }^{7}$ We also find 'bone' colexifying with 'thorn' in Jita and Mwotlap (along with many other meanings in the latter), with 'reed' in Totoró and Sema, with 'reed' and 'thorn' in Ngoreme, and with 'midrib' or 'central nerve' in reference to a leaf in Aisi, Mwotlap and many other Melanesian languages.

In Melanesia and Oceania, it is common for 'bone' to colexify with one or more items used as supporting frameworks. For example, Buang sekë is glossed 'bone,

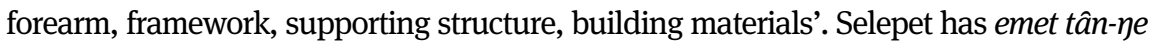

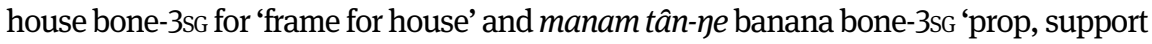
for a banana tree', while Kâte has fic siec house bone 'framework of a building' and jâc siec tree bone 'poles for a wooden structure, poles for the structure of a bush house'. Tuamotuan ivi colexifies 'bone' and 'ridgepole', while Mwotlap hyē colexifies 'bone' with 'ridgepole roping' which is described by François (2020) as the 'diagonal reinforcement supporting the roof structure linking the tie beams to the ridge beam [of a house]'.

A very rare association of 'bone' is with kin and origin groups. Maori has iwi for 'bone', 'people' and 'clan'. Amharic ațont colexifies 'bone', 'origin, family', while Tuvinian similarly colexifies сөөк 'bone' with 'tribe, clan, nationality, people'. The same association possibly underlies the Aghu expression axù-bigi human-bone 'clan', and the Kyaka Enga expression kuli renge bone origin 'ancestors, forebears'.

The lexical associations of 'bone' we have seen thus far have all been with nominal meanings that have concrete referents, but 'bone' is also observed to have associations with property concepts. These are highly infrequent. The meaning 'bone' colexifies with 'dry' in Burarra, Guraní and Meyah, with 'hard' in Ecun Buyang, Wappo and Bororo, and finally, with 'strong' (or 'strength' in some unspecified cases noted by Urban 2012: 622) in Ngambay, four Papuan languages of New Guinea and Ontong Java, an Austronesian language of Melanesia. The geographic clustering of the latter five languages suggests areal convergence may be at play, and it is this possibility that is taken up in the subsequent sections of this paper.

\section{Lexico-semantic association of bone with strength in Melanesian languages}

In what is now a canonical case of language contact, Ross $(1996,2001)$ describes "metatypy" on the basis of two unrelated Melanesian languages, Takia and

7 The latter two are, in terms of plant biology, the same structure, i.e., a hard, woody endocarp, that is, the innermost layer of the pericarp which surrounds a seed in a fruit. The thin membranous endocarps of, for instance, the seeds of an apple fruit, are presumably not salient enough to be distinguished from the seed itself. 
Waskia. These have come to have radically parallel linguistic organization as a result of Takia speakers' bilingualism in Waskia. A major component of metatypy is semantic reorganization whereby "equivalent lexical items in Takia and Waskia have the same range of meaning, closed sets of morphemes have similar membership and semantic structure, and complex lexical items, whether compound words, phrases, or larger formulae have been reformulated so that their component morphemes are the same as their Waskia equivalents" (Ross 2001: 144). Among the many features of semantic equivalence between them, Ross (2007) names Takia tatu and Waskia sokel as sharing the meanings 'bone' and 'strength'. A lexico-semantic association of bone with strength in fact goes well beyond Takia and Waskia; it is found widely in Melanesia, being expressed through a large variety of means across all levels of semantic organization named by Ross, both within and across languages. The similarity of the great variety of lexical expressions constructed at different morphosyntactic levels can, I argue, be captured using the formula BoNES ARE STRENGTH. By encapsulating the Melanesian lexicosemantic association in this way, it is my intention to abstract away from languageparticular idiosyncrasies in expressions and to capture the association that sees the having of bones as giving strength on the broadest level.

Before turning to an examination of the Melanesian data, it is important to note the partial character of the documentation of most languages in the area. This study is based on a survey of 180 languages in and around the Melanesian region. Data was gathered from dictionaries, grammars, texts, and through consultation with field linguists. However, even the lengthiest sources were often rather minimal in terms of the lexicographic detail they provided. Relevant collocations or complex expressions that would provide evidence for a lexico-semantic association of bone with strength were frequently not included in lexical materials. Or, as is the case for Takia and Waskia, an association may be noted in glosses, but examples illustrating contextualized use of the different senses were lacking. ${ }^{8}$ In total, 75 of the surveyed languages, all within the Greater Melanesia area, evinced a clear synchronic association of bone with strength. For those that did not, it is suspected that more complete materials, particularly texts, would in many cases yield a different result.

In what follows, the reader will encounter numerous lexical patterns and expressions underpinned by the association BONES ARE STRENGTH. Data was harvested

\footnotetext{
8 Another case was the Alekano dictionary where Deibler (2008) gives helisá with the meaning 'bone, strength'. However, there are no examples in the dictionary that show in what contexts helisá can be used with the meaning 'strength'. Such languages are not counted in the sample; the absence of examples meant that these languages could not be analysed and classified in respect to their construction(s), even though it seemed quite clear that the association was present.
} 
from sources by identifying item(s) meaning 'bone' and then creating lists of all lexemes, phrases and expressions that involved the 'bone' lexeme. ${ }^{9}$ This "wide net" data collection strategy revealed, in addition to a large data set for the BONES ARE STRENGTH association, linguistic expressions that are underpinned by several other recurrent lexico-semantic associations involving 'bone' in Melanesia. ${ }^{10}$ Only a portion of the amassed materials will be used to illustrate the large variety of the linguistic guises in which the BONES ARE STRENGTH association finds expression. For a complete set of the compiled materials by language, including details of all languages sampled, textual examples (where available), and sources, the reader is referred to Appendix I.

\section{1 'bone' = 'strong' and the pathways to colexification}

The Melanesian association BONES ARE STRENGTH can be manifested in an apparent strict colexification of 'bone' and 'strong'. In some of these languages, the colexification is heterosemic, with the different senses being associated with different morphosyntactic contexts. For example, Leti ruri has the sense 'bone' in nominal contexts (1a), but 'strong' in verbal contexts along with the expected morphology, i.e., in

9 In a few cases I also looked at particular target passages from translations of the New Testament, e.g., Matthew 12:29, Luke 16:3, John 6:18, Romans 15:1.

10 In addition to the many linguistic expressions underpinned by the most frequent association BONES ARE STRENGTH, there are two other recurrent associations involving 'bone' encoded by diverse expressions that came out during data compilation. The first is CONSISTING OF BONES IS BEING THIN/HAVING ONLY BONES IS BEING THIN. This very widespread association shows frequent extension from the meanings of 'thin', 'skinny' and 'bony' to others such as 'unhealthy', 'weak' and 'wasted'. Examples of the sorts of expressions coding the association include: Aghu bigi da only bone 'thin (of person)' (van den Heuvel 2016), Mali Baining slēp pēt viso bone LOC AUx 'skinny, bony' (Stebbins and Tayul 2012), Motuna koona nong bones only 'anorexic, unhealthy, very thin (person)' (Masa Onishi pers. comm.), Orokolo ukiila with bones 'bony, in a wasted condition'. There is a further, but much rarer, extension of the HAVING ONLY BONES IS BEING THIN association to refer to the elderly, e.g. Oksapmin hän tam sän person bone container/top 'old man' (Lawrence 2006), Komnzo ausi kam kam woman REDUP bone 'old woman' (Christian Döhler pers. comm.). Note that the HAVING ONLY BONES IS BEING THIN association, where the presence of bones indicates thinness/weakness, is not to be confused with the negative polarity version of BONES ARE STRENGTH, although their translated meanings on occasion converge. In a few languages, LACK OF BONES IS LACK OF STRENGTH is extended from 'weak' to 'skinny', as in Mende hava-mba bone-without 'be skinny' (Nozawa 2006), but here it is absence of bones (rather than their presence) that gives rise to extension to 'skinny'. The second recurrent, but rare association was THE BONE IS THE IMPORTANT/MAIN PART. This association is found, for instance, in the Mek languages, for example, Yale yoo ina bone path 'main path, important way', Eipo asik yok-nang hamlet bone-people 'people of a central hamlet (one with a men's house, not a newly founded garden village)' (Volker Heeschen pers. comm.). 
predicative function marked by either a stative verb suffix (1b) or a dynamic verb prefix (1c), and in attributive function with dependency marking reduplication (1d).

(1) Leti $^{11}$
a. pipruri
pipi-ruri
goat-bone
'goat bone'
b. lo rurni
loi ruri-ni
canoe bone-3sg
'The canoe is strong!'
c. lo naruri
loi na-ruri
canoe 3sg-bone
'The canoe gets strong!'
d. lorururi
loi $=$ ru $\sim$ ruri
canoe $=$ REDUP $\sim$ bone
'strong canoe'

In other sampled languages, however, we find no morphological marking associated with different syntactic contexts in which the meanings 'bone' and 'strong' are found. The Papuan language Ambulas typifies this pattern: apa can be used nominally to mean 'bone' (2a) and predicatively to mean 'strong', either as a stand-alone predicate (2b) or with do-support (2c). Apa is also used adnominally with the meaning 'strong' (2d).

(2) Ambulas
a. apa dé tékwiyaa-k
bone 3sG broken-PST
'The bone was broken.'
b. wani nyéga apa yamarék yate dé nyéknwu DEM leaf bone NEG and 3sG go.slack:3

'That leaf is not strong and it goes slack.'
c. apa mé ya! bone IMP do 'Be strong!'

d. apa $d u$

bone man

'strong man'

11 See Appendix I for sources and ISO 639-3 codes of all data mentioned in this article. 
In each of these syntactic appearances, apa behaves in accordance with the word class properties that its respective meanings would predict. That is, in its nominal appearances it behaves as a noun would be expected to, while predicatively and adnominally it shows behaviour consistent with a stative verb/adjective. As such, Ambulas apa can be taken to represent a straightforward case of strict bone/strong colexification. Ambulas is unique in this, due to its unusual word order profile: like most other Papuan languages it has SOV and Genitive-Noun orders, but atypically for a Papuan language it combines this with Demonstrative-Noun, AdjectiveNoun and Relative clause-Noun orders. This means that there is no way in Ambulas to distinguish between adjectives and other kinds of noun modifiers based on their ordering relative to the noun.

This is, however, not the case for the vast majority of Melanesian languages, where most modifiers, apart from possessors, follow the noun. A case in point is Aisi which, at least superficially, has strict bone/strong colexification. Nominally, dagar has the meaning 'bone' and by extension 'strength' (3a), but it can also appear meaning 'strong' predicatively (3b) and adnominally (3c). In Aisi, an adjectival modifier would normally follow the noun (Don Daniels pers. comm.). In (3c) adnominal dagar appears before the head noun $k i$ 'speech' as a possessor would, thereby indicating that dagar synchronically has the status of a noun. If this analysis is correct, the predicative appearance of dagar in (3b) would need to be analysed as an equative constructive (literally, 'your livers are not bones').

Aisi

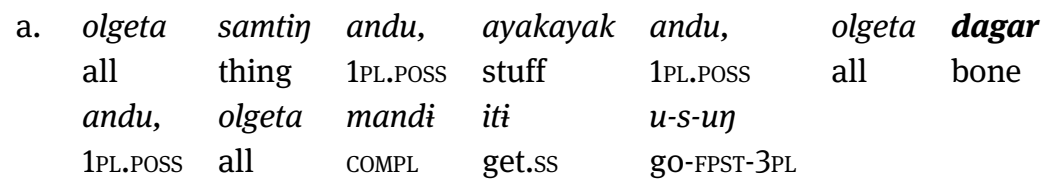

'Everything of ours, all our stuff, all our strength, they took it all away.'

b. umbay narikun dagar ma

liver 2PL.POSS bone NEG

'Your wills are not strong.'

c. dagar $k i$

bone speech

'strong speech'

The fact that Aisi dagar does not have the expected syntax of an adjective in its adnominal use, suggests that conversion is not taking place and that dagar is still a noun.

In another language with bone/strong colexification, we do have positive evidence that conversion takes place. In Pamosu, a modifying noun precedes the 
head noun, as in (4a). However, when kenav 'bone' is used with the meaning 'strong' it unexpectedly follows the head noun (4b). Pamosu has a further restriction: kenav does not appear predicatively with the meaning 'strong'; the adjective pelat 'strong' is used in predicative contexts (Ian Tupper pers. comm). These features set the Pamosu colexification apart from that presented by Aisi (3c).

(4) Pamosu
a. na
kenav
tree bone
'branch' (lit. tree bone)
b. waia kenav
wire bone
'strong wire'

The morphosyntactic differences in these appearances of 'bone' lexemes with the sense 'strong' goes back to the diversity of possessive structures and their functions in Melanesian languages. I posit that the starting point for the emergence of the colexification of 'bone' and 'strong' is the contextual use of 'bone' in an adnominal possessor construction to mean 'strong'. This can be illustrated with the Ekari expression in (5a) where mitoo 'bone' modifies mer 'man'. Here, the modifying noun precedes the head noun, consistent with a possessive noun + noun compound structure (as in 5b). Notably mitoo mer is the sole known expression in Ekari where mitoo is used with a contextual relationship to strength, but it is presumably from such a construction that the pattern we see in Aisi (3c) above was extended to modifying more referent types. ${ }^{12}$

(5) Ekari
a. mitoo me:
bone man
'strong man'
b. boko mitoo
breast bone
'breast bone'

Alternatively, the 'bone' lexeme that contextually comes to denote 'strong' may begin constructionally as the possessed item. It is common in parts of Melanesia

\footnotetext{
12 A likely progression for the contextual extension of 'bone' to the meaning 'strong' is of male $>$ human $>$ animate $>$ inanimate. In fact, it is quite common in my data that 'bone' can only be used with an association to strength for animates. See, for example, Bilua's use of piza 'bone' to mean 'strong', which is limited to human referents, while in Buin kaana-raake 'bone-with/have' is used for 'strong' of both humans and animals (discussed further in Section 4.2).
} 
for attribute constructions to have the morphosyntax of possession: the noun denoting the class of referent behaves as if it were the possessor and the attribute as if it were the possessed (Ross 1998). We see in (6a) that Jabêm têkwa 'bone' denoting 'strong' has the identical morphosyntax to the possessed item legu? 'tail' in (6b). Such a construction is the likely source for the use of Pamosu kenav after the head noun (in an adjective-like position) to mean 'strong'.

(6) Jabêm
a. nac
na-têkwa
man Poss-bone
'strong man' (lit., man's bone)
b. keam ya-legu?
dog poss-tail
'dog's tail'

The important point for the reader to take away here is that there are subtle differences between languages in the morpho-syntactic behaviour of 'bone' lexemes when expressing the meaning 'strong' that are indicative of the pathways along which colexifications emerge. While these details do not impact on their status as colexifications for the model as developed by François (2008), they do have implications for how we detect and collect data on such lexico-semantic associations. Because the morphosyntactic contexts in which 'bone' and 'strong' colexify in these languages are highly varied, elicitation situations - such as when collecting a word list or completing a questionnaire - are unlikely to be sufficiently detailed for heavily contextualized or restricted colexifications of 'bone' and 'strong' to come out, especially where they exist alongside a more general property word meaning 'strong', as is the case with most of the languages examined in this section.

\subsection{Derived 'bone' = 'strong' and the morphology/syntax divide}

Loose bone/strong colexification occurs where the meaning 'strong' (or a related meaning) is morphologically derived from 'bone'. In the present sample, this is found in the following 12 languages: ${ }^{13}$

13 Note that I include cases of derived 'bone' = 'hard', because the differentiation of 'strong' and 'hard' is weak in many Melanesian languages, reflecting an animate and inanimate divide. Also, strong/hard colexification is common in the world: see https://clics.clld.org/edges/785-1884. 
(7) Buin kaana 'bone' > kaana-raake bone-with 'strong (of human, animal)' Kwoma hapa 'bone' > hapa-ga bone-sim 'strong' Ngkolmpu mpar 'bone' > mpar-wa bone-ADJ 'hard, firm, solid' Daga kaim- 'bone' > kaim-ake bone-ADJ 'hard' Sentani bo 'bone' > bo bo REDUP bone 'strong, hard, firm'

Mekwei den 'bone' > den den REDUP bone 'strong'

Tukang Besi buku 'bone' > me-buku ADJ-bone 'strong'

Tontemboan ruPi 'bone' > ma-ruPi ADJ-bone 'hard'

Kambera rí 'bone' > pa-rí cTR-bone 'strong'

Bola tuha 'bone' > tuha-ka bone-ADj 'strong'

Nakanai tuha 'bone' > tuha-ka bone-ADJ 'very hard-working, strong (of person)'

Tolo suli- 'bone' > su suli-ha REDUP bone-ADJ 'strong'

The line between morphological derivation and syntactic construction becomes blurry, however, when we interrogate the broader functions of the morphemes that are used to derive the forms meaning 'strong' in (7). For instance, Buin -raake not only functions to derive property words from nouns (8a) and verbs (8b), but also introduces participants with comitative (8c), accompaniment (8d) and instrumental roles (8e). Finally, -raake can also be used for denoting predicative possession (8f). In the Buin dictionary, Laycock (2003) glosses -raake as 'have, in possession of'. The range of its meanings seen in (8) is, however, consistent with a comitative marker which is also used in the expression of possession, as is crosslinguistically common (Heine 1997: 77).

(8) Buin -raake

a. inna-raake

blood-raake

'mess of blood, bloody'

b. koni-raake

lie-raake

'lying, deceitful'

c. ina ruka iko-raake

wife:1sG man:PL DEM.M-raake

'my wife with all those men'

d. ako noke mokokotu minno-paaroi karapana-raake

DEM some spear follow-TAM poison-raake

'some spears accompanied by poison'

Section 4.4 deals with the different extended senses of BONES ARE STRENGTH that are present in the surveyed language data. 


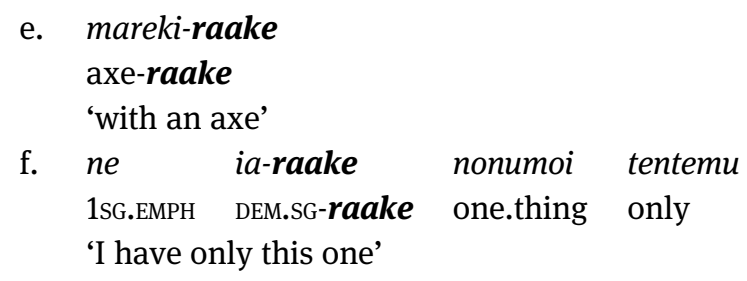

The problem for a comparative study here is that it is not clear that there is a truly principled way to separate out instances using morphology, like Buin kaana-raake bone-with = 'strong', from languages such as those in (9). In these, phrases composed of a free adposition meaning 'with' plus a noun 'bone' are used to express 'strong'. The adpositions have a range of functions that overlap with those of Buin -raake, introducing comitative and instrumental participants etc., and thus differ to a large extent only in their boundness.

(9) Mehek

$$
\begin{array}{ll}
\text { a. } & \text { yefa } \quad \text { kana } \\
\text { bone } & \text { with } \\
\text { 'strong' (lit. (be) with bone) }
\end{array}
$$

Sinaugoro

$\begin{array}{llll}\text { b. maitau } & \text { tu } & \text { ma } & \text { turiya-na } \\ \text { DEM } & \text { man } & \text { with } & \text { bone-3sG }\end{array}$

'This man is strong' (lit. this man is with his bones)

Mota

$\begin{array}{lll}\text { c. ineia } & \text { mun } & \text { na-suri-na } \\ \text { 3SG } & \text { with } & \text { ART-bone-3SG }\end{array}$

'He's strong' (lit. he is with his bones)

This appears to be a case of "what is one language's morphology is another language's syntax". From the point of view of the current study, if we were to draw a strict line at the simple lexeme or even morphologically derived lexeme as the sole unit of investigation, to the exclusion of phrases, then the lexico-semantic association of bone with strength that both the languages in (7) and those in (9) share would not be captured.

If we do regard syntactic units such as adpositional phrases 'with bone' = 'strong' alongside complex lexical ones as comparable analytical units, then the question quickly arises as to whether it is principled to exclude 
non-phrasal predications of similar meaning. Numerous sampled Melanesian languages express 'strong' by means of a clause in which a form meaning 'bone' is the subject of the clause with an 'exist' verb as predicate; the person whose strength is at issue is encoded as the possessor of the subject 'bone'. Examples of this type are given in (10). ${ }^{14}$

Bena-Bena

a. felisa- $a$ ni’ $i-v e$

bone-3sg exist:3sG-DECL

's/he is strong' (lit. his/her bones exist)

Melpa

b. ompedl mugli

bone exist

'(s/he) is strong, powerful' (lit. bones exist)

Eibela

c. ki: la: $\quad m a$

bone exist NEG

'(s/he) is weak' (lit. bones do not exist)

It seems apparent that clauses such as those in (10) are actually just another linguistic form of expressing what is captured by derived lexemes in (7) and adpositional phrases in (9). Aiton (2016: 138-142) even points out in relation to the Eibela example (10c) and other similar constructions in that language that these clauses are readily used adnominally and show signs of lexicalizing into adjectives. ${ }^{15}$

In short, the lexico-semantic association BONES ARE STRENGTH is expressed in the languages of Melanesia not simply through simplex or complex lexemes, but also by constructions that are phrasal and even clausal. It is by no means novel to regard the boundary between grammar and lexicon as fluid (see, e.g., Fillmore et al. 1988). Nonetheless, in the context of increasing moves to automatize colexification studies, it is important to recognize the limitations of a lexeme-based view of the lexicon.

14 Note that I regard LACK OF BONES IS WEAKNESS, for instance in (10c), as simply a negative polarity version of the association BONES ARE STRENGTH.

15 Similar adnominal constructions of 'bone exist/have' = 'strong' are in evidence in Bena-Bena and Manambu. The reader is referred to Appendix I for examples. 
Table 2: Constructions of 'bone' + negative morpheme (+verb).

\begin{tabular}{|c|c|c|c|}
\hline Bosavi & kí-do'ma & bone-without & 'really weak after illness' \\
\hline Kamano & zferina omne & bone without & 'feeble, weak, weary, tired' \\
\hline Yagaria & -apuva-'ago' & bone without & 'lacking power' \\
\hline Maybrat & -tai-kah bo fee & bone-with AUX NEG & 'have no energy to work' \\
\hline Fore & ayampú kampá píye & bone NEG do:AUX & 'feel lazy or tired or weak' \\
\hline Manambu & ap ma: to & bone NEG have & 'soft, weak, meek (person)' \\
\hline Eibela & ki: la: ma & bone exist NEG & 'weak' \\
\hline Kobon & le mid-ag- & bone be-NEG & 'weak' \\
\hline Bena-Bena & felisa-me ni'i- & bone NEG exist & 'weak, tired' \\
\hline Yagaria & -apuva a'-hane & bone NEG-exist & 'weak' \\
\hline Melpa & ompedl kel mugli & bone NEG exist & 'physically weak, not fit' \\
\hline Buang & seḳe ma & bone NEG.EXIST & 'have no strength' \\
\hline Mwotlap & hyē-tateh & bone NEG.EXIST & 'have no strength' \\
\hline Buin & kaana tounoke teumoi & bone nothing be & 'weak (person)' \\
\hline Mauwake & oona marewag & bone have.none & 'lazy’ \\
\hline
\end{tabular}

\subsection{Idioms associating bone and strength}

Phrasal and clausal constructions expressing the association BONES ARE STRENGTH qualify as idioms in that they are polylexemic expressions of a single semantic unit that cannot be understood as having the literal meaning of their constituent parts.

In comparing the different expressions across languages, we can see that the constructions used in many languages are striking similar. For example, Table 2 presents the constructions expressing LACK OF BONES IS WEAKNESS, the negative polarity version of the BONES ARE STRENGTH association, that are made up of the lexeme 'bone' plus a negative morpheme (and, where necessary, a verb). In each language, the exact make-up of the construction is different according to the specific languageinternal resources available. Their meanings (as represented here by glosses taken over from individual linguistic descriptions) are also not exactly same across languages, but are broadly similar enough to be regarded as instantiations of the same lexico-semantic association.

The lexico-semantic association of bones and strength is also widely expressed in the languages surveyed with constructions of the shape 'bone' + 'weak/soft' (Table 3) and 'bone' + 'strong/hard' (Table 4). Again, the meanings expressed by these constructions are not identical, but can still be traced back to a common association, BONES ARE STRENGTH. More specifically, we could describe these expressions as representing a figurative seating of strength in the bones. Melanesian languages (and perhaps all languages, according to Enfield and Wierzbicka 2002) typically have a range of fixed expressions that convey emotions 
Table 3: Constructions of 'bone' + 'soft/weak'.

\begin{tabular}{|c|c|c|c|}
\hline Kalam & tni sayn & bone soft/weak & 'weak, frail, lethargic' \\
\hline Wahgi & embetem tamb & bone soft/weak & 'coward' \\
\hline Melpa & ompedl reimp & bone soft & 'weak, feeble' \\
\hline Kâte & siec dodoc & bone weak & 'tired' \\
\hline Baruya & yagi-wirita & bone-weak & 'weak from sickness' \\
\hline Meyah & oforá eriaga & bone weak & 'weak, feeble' \\
\hline Mokona & oforna egerag & bone weak & 'lethargic' \\
\hline Jabêm & têkwa gali & bone soft & 'undeveloped, half-grown' \\
\hline Mwotlap & hyē- mdawdaw & bone- soft & 'weak' \\
\hline Muna & maluso buku & weak bone & 'exhausted' \\
\hline Tolaki & molulu $\beta u k u$ & weak bone & 'weak, tired' \\
\hline
\end{tabular}

Table 4: Constructions of 'bone' + 'hard/strong'.

\begin{tabular}{llll}
\hline Kalam & tni kls & bone hard/strong & 'physically strong, energetic' \\
Bosavi & kío: halaido: & bone strong & 'strong' \\
Mangalasi & ata kaisin & bone hard & 'strong (person), determined' \\
Meyah & oforá efék & bone strong & 'strong, persistent, stubborn' \\
Moskona & oforna ahaysa & bone hard & 'invulnerable' \\
Moskona & oforna owas & bone strong & 'adversarial' \\
Mwotlap & hyē- - maymay & bone hard & 'strong' \\
Lewo & purya kawa & bone strong & 'strong' \\
Muna & ghosa buku & strong bone & 'strong' \\
Tontemboan & kate ruPi & hard bone & 'strong (of muscles), adult' \\
\hline
\end{tabular}

and personal characteristics involving a figurative seating in the body. These "seats" manifest themselves in linguistic constructions involving, often lexicalized, body part + predication constructions, such as is the case in Tables 3 and 4. Typically, one body part will be the main seat of emotions/traits in a language; it is frequently the case, however, that particular semantic clusters of emotions/traits (e.g., anger, violence, etc.) will be seated in their own distinct body part. ${ }^{16}$

For many of the languages sampled here, idioms expressing the association BONES ARE STRENGTH and LACK OF BONES IS WEAKNESS were not simply a matter of negated (i.e., "bone exist' = 'strong' vs. 'bone not exist' = 'weak') or antonymous constructions (i.e., 'bone strong/hard' = 'strong' vs. 'bone weak/hard' = 'weak'). Rather, a large number of

16 For instance: in Bunaq mil 'insides' is the figurative seat of emotions and the mind, while anger is seated separately in the gotok 'liver' (Schapper fieldnotes); in Motu, lalo 'insides' is the seat of the affections and thought, while boka 'stomach, belly' is the seat of desire and pity (Lawes 1896). 
idioms of unique or near-unique formation were attested. For example, while Mehek 'with bone' = 'strong' (11a) finds close parallels in numerous languages in the sample, the antonymous idiom 'empty bone' = 'weak' (11b) is unique, even though it is clearly similar in import to 'bone' + negative morpheme = 'weak' expressions in Table 2.

$$
\begin{aligned}
& \text { Mehek } \\
& \begin{array}{l}
\text { yefa kana } \\
\text { bone with } \\
\text { 'be strong' }
\end{array}
\end{aligned}
$$

In fact, there is a huge amount of variation in the form of idiomatic predications involving 'bone' to express 'strong' and 'weak'. Examples in (12) and (13) present a few of the constructions involving 'bone' plus a verb of variable meaning that are used to express the referent's strength or lack thereof.

Ulwa

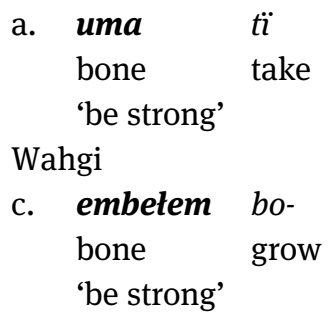

(13) Fasu
Yagaria

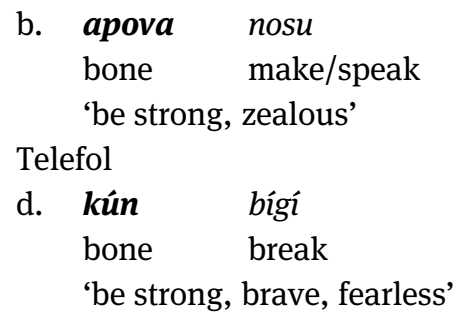

Kâte
Kewa

$$
\begin{aligned}
& \text { a. kikí fárakala } \\
& \text { bone finished } \\
& \text { 'be weak, paralysed' }
\end{aligned}
$$
c. uni oma pa-
bone die make 'be weak'
b. siec wauc
bone loose
'be weak, unstable'

Angave
d. eyi' apearini
bone crawl
'be weak'

I do not claim that the different idioms presented in this section are interchangeable in all contexts. The variation in glosses associated with 'bone' + predication constructions plus the fact that numerous languages surveyed exhibit multiple 'bone' + predication constructions make clear that there are semantic differences between the various idioms. For our purposes, however, it is enough that they possess a common image component on the lexical level: these idiomatic expressions use lexemes for 'bone' to figuratively stand for strength as part of a common association which I have expressed as BONES ARE STRENGTH. In Dobrovol'skij and Piirainen's (2010) typology of idioms, this means the idioms discussed here have a "symbol-based motivation", that is, they exploit "certain cultural conventions based on the ability of material objects to “stand for” some non-material entity' (Dobrovol'skij and Piirainen 2010: 79). In this Melanesian case, bones are shared cultural symbols of strength. Whilst the association 
is shared, the ways to express it are language-specific; a handful of recurrent constructions with 'bone' lexemes exist alongside a large number of unique idioms involving 'bone'. Recognizing the shared association despite the diversity of idiomatic constructions is crucial in order to identify the areal pattern here.

\subsection{A semantic map of the Melanesian association BONES ARE STRENGTH}

In the previous sections, we have focussed on the use of the BONES ARE STRENGTH association with respect to physical strength in humans and animals (i.e., HAVING BONES IS HAVING PHYSICAL STRENGTH). Whilst this is certainly the most widely found sense of the association, the different glosses we have seen accompanying idioms have hinted at the numerous semantic extensions found in the data. In this section, I illustrate the patterns of extension of the BONES ARE STRENGTH association that came out of the gathering of contextualized attestations of 'bone' lexemes. The reader is referred to Appendix I for the complete dataset.

Figure 1 presents a tentative semantic map of the various semantic connections between the senses that are expressed by BONES ARE STRENGTH. The ordering of senses on the map represents my own intuitions about what constitutes a semantically plausible

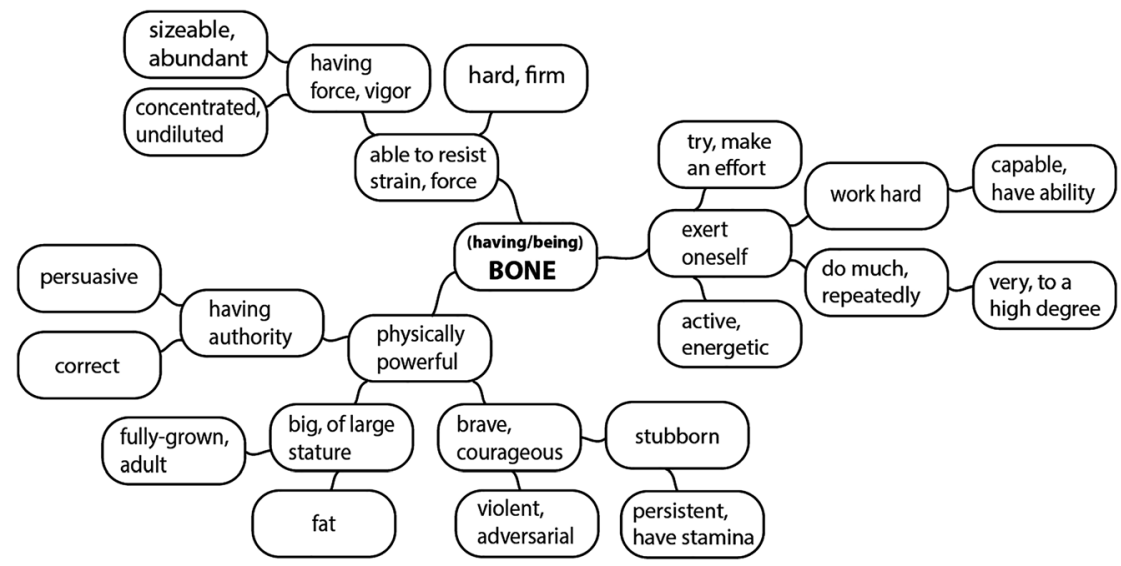

Figure 1: Tentative semantic map of bone's lexico-semantic associations with strength in Melanesia.

ordering based on my reading of the data. I also choose for simplicity's sake in the visualization to link the senses I distinguish together in relatively linear chains. In reality the relationships between senses are more web-like with many connecting lines running between different senses. According to common semantic properties, I group the senses 
reflecting the BONES ARE STRENGTH association into three clusters, which will each be discussed briefly in what follows.

The first cluster in the lower left-hand corner of the map pivots on the association HAVING BONES IS HAVING PHYSICAL STRENGTH. Used typically in reference to humans, the association has three recurrent semantic extensions in the data. The first extension is reflected as HAVING BONES IS HAVING LARGE SIZE, with further, less frequent extensions to being fat or fully developed:
Selepet
Wolio
a. tân-niak tân-niak
REDUP bone-with
b. ma-oge
buku-na
'be heavily set'
STAT-big
bone-3sg
Jabêm
'be big and fat, strongly built'
c. têkwa gali
bone soft
'be undeveloped, half-grown'
Tontemboan
d. kate rupi
hard bone
'be strong of muscles, adult'

HAVING BONES IS HAVING PHYSICAL STRENGTH regularly extends to social meanings such as in reference to a person's mental ability to deal with and endure dangerous or painful situations (i.e., HAVING BONES IS HAVING COURAGE), illustrated in (15).

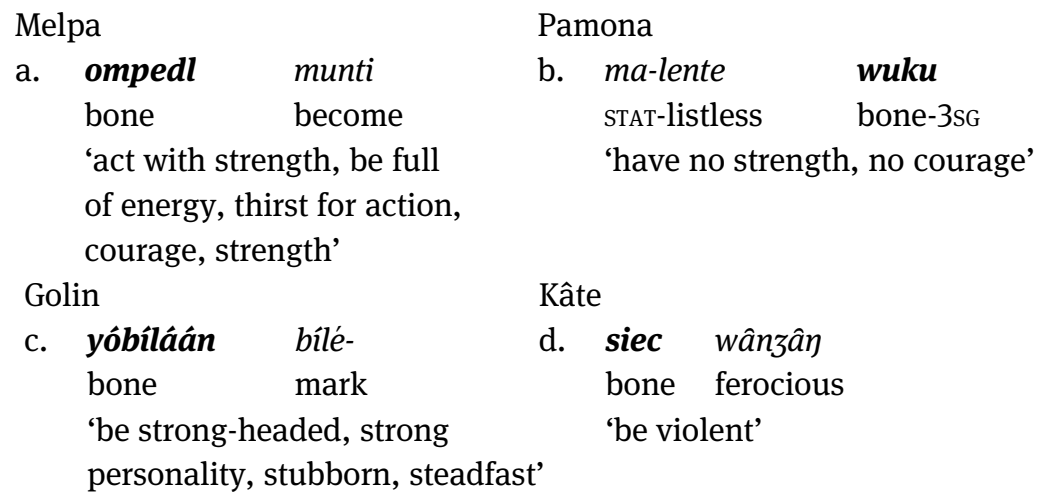

In Melanesia, exhibitions of physical strength are key to political power and authority; so-called "big men" do not govern by inheritance or command, but influence the group through individual example (Sahlins 1963). Accordingly, extensions to a person's ability (or their speech's ability) to command authority or have controlling political power by reason of character (i.e., HAVING BONES IS HAVING POLITICAL POWER) are also in evidence in the data (16). 
Telefol
a. kún
tébe-sú
bone become-TAM
(1) 'strong, firm, hard'
(2) 'has authority, power'

Rotokas
c. keru-ria reo-to
bone-DER talk-3sG.m
'persuasive talker'

Kwoma
b. maji
hapa-ga
word
bone-ADJ
'a factually correct, morally acceptable, or authoritative statement'

The data also show semantic extensions which involve chiefly inanimate referents and indicate their ability to support strain or withstand force (broadly, BONES ARE HARDNESS). Represented by the cluster in the top left of the semantic map, the extensions in this cluster are found in a relatively small number of languages. Many of these can be illustrated by Ambulas apa 'bone', which when used adnominally to nouns with inanimate referents has a wide range of senses:

(17) Ambulas

a. apa yakwa kadému nébi-t wuné sagule k-o bone REL food tooth-1SG 1SG bite consume-PRS 'I bite hard food with my teeth and then I eat it'

b. apa maas viyaa-dék dé taabun-ba paaku-k bone rain hit-? 3SG overhang-Loc shelter-PST

'Heavy rain fell so he took shelter under the roof overhang'

c. ken apa jebaa naane ya-k FOC bone work we do-PST

'This is big work that we do'

d. bulaa kén apa yéwa-at de kérao now FOC bone money-with 3PL buy

'Now it is with much money that they buy (them)'

The third cluster, located on the right-hand side of the semantic map, involves extensions of the association of 'bone' with physical strength to include physical exertion and intense activity (broadly, HAVING BONES IS EXERTION). Senses in this cluster are frequently expressed with verbal and adverbial uses of 'bone' lexemes, such as those illustrated in (18).
Wolio
Motu
a. ko-buku
b. turia turia
INTR-bone
REDUP bone
'exert oneself'
'energetically, vigorously' 
Rotokas
c. kaim-akaet wapen
$\begin{aligned} & \text { bone-ADV say } \\ & \text { 'speak sternly' }\end{aligned}$
Banggai

d. buku-an ba-susup
bone-ADV INTR-suck
'smoke a lot'

Idiomatic expressions in this domain are also numerous. These show recurrent patterns of extension to meanings related to strenuous work based on the association WORKING HARD IS USING ONE'S BONES. The examples in (19) present some of these idioms.

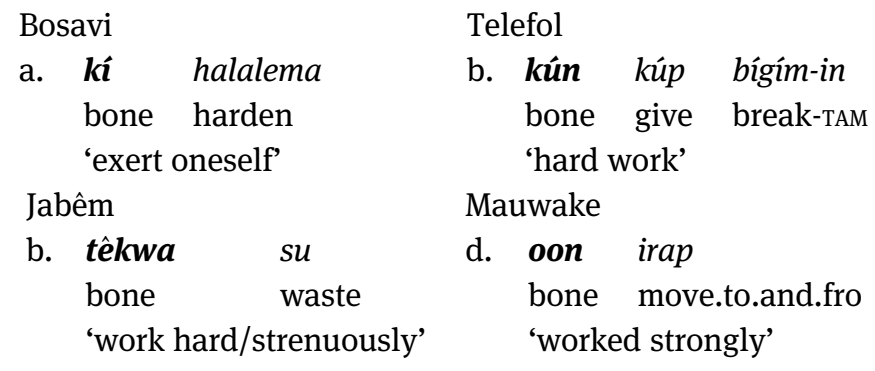

Rarer extensions within this cluster are to contexts of effort and capability in carrying out actions, as in the following expressions:

Meyah
a. éij oforá efék
throw bone hard
'endeavour'
Maybrat
c. n-tai
3-bone
'able, capable'

Kamano
b. zferina eri avuga ante'nee bone give in.front put 'make an effort'
Makasar
d. a'-buku-bassi ACT-bone-iron 'able to carry out heavy work'

In short, the lexico-semantic association of BONES ARE STRENGTH, in addition to taking a wide-range of forms, has a wide-range of semantic extensions in the languages of Melanesia. These connections become clear when contextualized attestations of 'bone' lexemes are gathered together. Without these collected together in a large database, it would not be possible to observe and show the recurrent semantic extensions of 'bone' lexemes across Melanesia. 


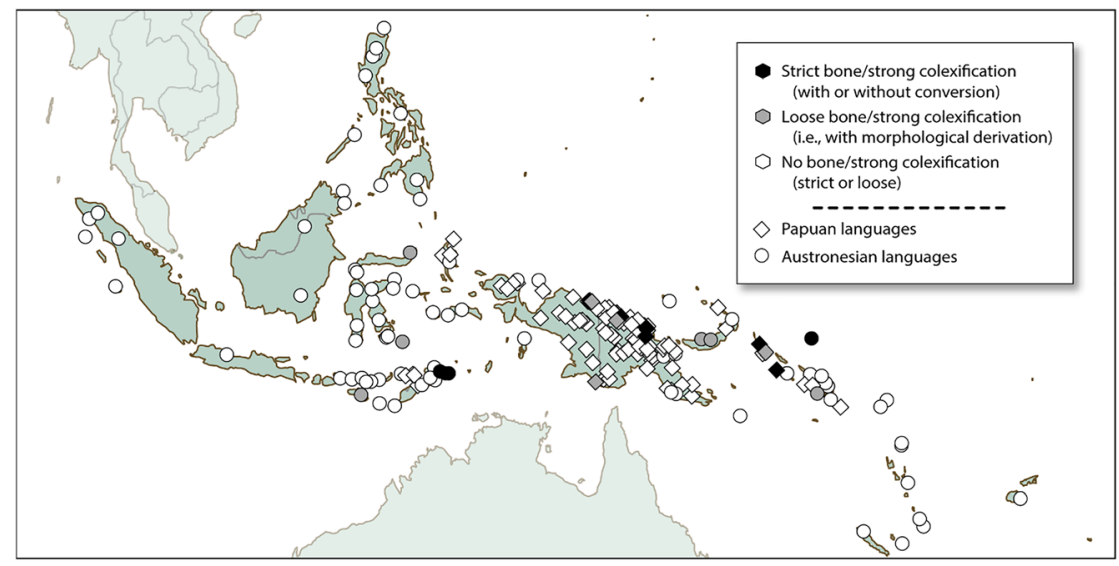

Map 1: bone/strong colexification in Melanesia.

\section{Areality in Melanesia}

If we map the surveyed Melanesian languages for the colexification of 'bone' and 'strong', the result is an extremely scattered distribution (Map 1). Strict bone/ strong colexification (see Section 4.1) is found in only a handful of the languages surveyed. Loose bone/strong colexification, where 'strong' is derived from 'bone' by a morphological process occurs in a further 12 languages. In short, only taking into account these narrowly defined colexifications would mean that the areality of this broader areal feature in the form of a linguistic association is not captured.

By contrast, the lexico-semantic association BONES ARE STRENGTH is found in 75 of the 180 languages sampled across Linguistic Melanesia (Map 2). The core area for the lexico-semantic association is in northeast New Guinea, with numerous outlying groups to the east and west. In the core area, the lexico-semantic association is dispersed across unrelated language families, including Sepik, Ndu, Ulampo, Torricelli, Border, Sentanic, Nimboran and numerous members of distinct Trans-New Guinea subgroups. Outside this core, there appears to be a loose cluster in the Bird's Head and Bird's Neck regions, Sulawesi and around Timor in the far west, and a group of local centres in the Bird's Tail and Island Melanesia, where both Austronesian languages and Papuan languages of diverse families display the association. The skewed nature of the distribution, combined with the occurrence of the association over numerous language families, indicates areal pressures at play. Similar areal distributions have been found for other linguistic 


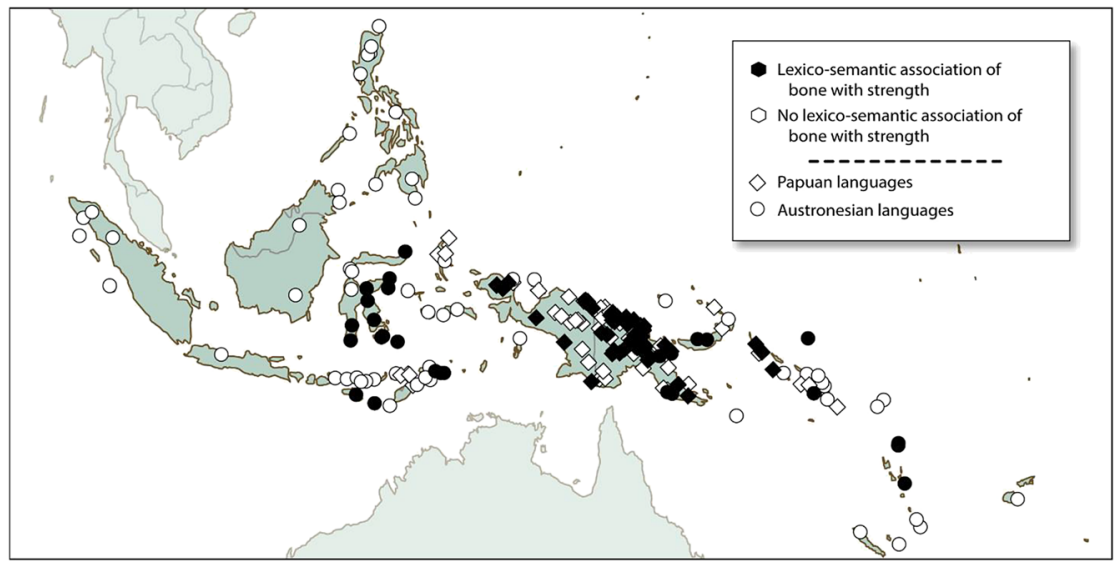

Map 2: Lexico-semantic association of bone with strength in Melanesia.

features in Melanesia, most notably the prenasalization contrasts described by Donohue and Whiting (2011). ${ }^{17}$

Discussing Manambu, Aikhenvald (2008) suggests that the association between bone and strength has arisen in that language under influence of Tok Pisin, the lingua franca of Papua New Guinea. Tok Pisin has the linguistic association of bone and strength, as exemplified by the expressions in (21).

(21) Tok Pisin

bun 'bone, skeleton, framework' (Mihalic 1971)

draipela bun 'a strong man, a brave man, a tough fellow'

mi gat bun 'I am strong, I have the strength'

yu askim bun bilong mi? 'do you wish to try my strength?'.

yu no gat bun 'you are a weakling'

There are, however, several points that speak against attributing the association in Melanesia languages to influence from Tok Pisin. First, the association extends well beyond Papua New Guinea where Tok Pisin is spoken, being found also in languages of Indonesia, the Solomon Islands and Vanuatu. It is not known in

17 The reasons for this distribution are not understood. It may be an artefact of the level of documentation for western New Guinea. Outside of the Bird's Head at the western extreme of New Guinea, there is very little modern documentation of the non-Trans New Guinea languages of western New Guinea. At the same time, there is a relatively limited picture of the linguistic prehistory of New Guinea in general, but the western half of New Guinea is particularly unknown. The large areas covered by quite closely related languages of the Trans-New Guinea family in western New Guinea is suggestive that region is a relatively recent spread zone. 
Malay/Indonesian, nor is it documented for Bislama or Solomon Island Pijin, the other English-lexifier creoles of Melanesia related to Tok Pisin. Second, there appears to be regional variation in the Tok Pisin expressions using 'bone' in association with strength. For instance, bun i dai 'bone die' and bun pinis 'bone finish' for expressing loss of physical strength appear to be used in Tok Pisin varieties on the north coast of New Guinea, where similar expressions exist in local languages. This is suggestive of local languages influencing the forms of the expressions in Tok Pisin.

This view is reinforced by the diversity of constructions and expressions across languages in Papua New Guinea. Languages that are known to be in contact, like Manambu and Kwoma languages (Bowden 1997: 337-339, Aikhenvald 2008), bear little similarity to one another in the way they express the association. Both languages use the lexeme meaning 'bone' to denote the property concept 'strong, hard': the Kwoma form hapa-ga is derived morphologically by means of the similative suffix - $g a$ 'like' (22a); Manambu, however, does not use its similative suffix, but instead has a phrase consisting of ap 'bone' plus the verb ta 'have' to mean 'be strong' (22b).

(22) Kwoma
a. diita me hapa-ga tawa
this wood bone-like is
'This wood is hard'
Manambu
b. samasam-a ap to-na-d-ə mi lot-Link bone have-Act.Foc-3.M.SG.vT-LINK wood 'very hard wood'.

Equally, we find little similarity in the form and the meaning of idioms which are underpinned by the association between bone and strength in the two languages:

(23) Kwoma
a. maji hapa-ga
word bone-like
'a factually correct, morally acceptable, or authoritative statement'
b. tapa hapa-ga
word bone-like
'powerful hand (of sorcerers)

(24) Manambu
a. wun- $a$
ya:l ap taka-na
1-LINK.SG.FEM belly bone put-Act.Foc.3.F.SG.BAs.vT
'I have no appetite'. (lit. my belly puts bone) 


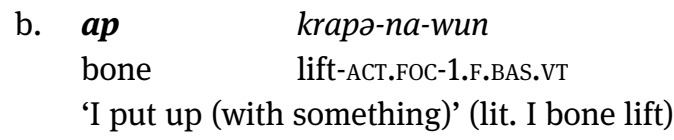

Even closely related languages such as sister languages Meyah and Moskona (25) or Kalam and Kobon (26) often have idioms which are underpinned by the association of bone with strength, but whose form-meaning pairings are to a large extent language-specific.

(25) Meyah

a. oforá efék bone strong 'be strong'

oforá eriaga bone weak 'be weak, feeble'

oforá ekeni bone red 'be bold'

Moskona

b. oforna ahaysa bone hard 'be invulnerable'

oforna egerag bone weak 'be lethargic, lacking in energy, lazy'

oforna owas bone strong 'be adversarial, like to fight'

(26) Kalam

a. tyi ay- bone put/form 'be strong, energetic', 'be fierce, aggressive'

tyi $k l s$ bone hard/strong 'physically strong and active, energetic'

tyi sayn bone soft/weak 'weak, frail, lethargic'

tyi tmey bone bad 'very strong, very fast (of a person)'

Kobon

b. le l- bone put 'be strong, exert oneself'

le l-ag- bone put-NEG 'be weak'

le mid-ag- bone be-NEG 'be weak'

Bilingualism with Tok Pisin is very recent in much of PNG, and although its influence has been in many cases radical (Kulick 1992), we would expect greater similarity in the constructions and expressions relating bone and strength, both between Tok Pisin and local languages and between individual local languages, if Tok Pisin was the ultimate source for the association. The lack of similarity in the language-specific expressions points to substrate influence from local Melanesian languages as having given Tok Pisin its association of bone and strength and not the other way around.

How did this association come to be spread over such a wide area? Melanesia has been characterized as an area in which there is widespread convergence in structural features of language but divergence in lexicon (see different descriptions of this setting in, e.g., Foley 1986: 283; Ross 2001; Thurston 1987, 1989). 
Laycock (1982), for example, writes that because many adjacent languages in Melanesia have very similar morpho-syntactic structures, learning another language is largely a matter of learning new lexicon- "that is, the two languages involved are very close to being the same language with a different set of labels". This situation is thought to have arisen out of documented patterns of language contact whereby long-term, stable multilingualism between speech groups leads to similar structural features being used in both languages, while the emblematic function of words, as the most salient markers of identity for speech groups, acts as a brake on adoption of foreign word-forms. In addition to a simple prohibition on borrowing lexemes, there appears to also have been processes in Melanesia whereby speech communities in frequent contact with one another deliberately enact changes to their languages, such as spontaneous innovation of distinctive word-forms or complex language structures to mark their identity as distinct from their neighbours (Laycock 1982; Schapper 2020). The shared lexico-semantic association discussed here is parallel to this structural convergence-lexical divergence model of the Melanesian Language Area: the association of bone with strength represents the underlying "structural" template that has undergone convergence, while the "lexical" forms by which the association is expressed are highly divergent, with each group having language-specific means for capturing the association.

A final question to be considered is: how significant is the areal association of bone with strength in Melanesia in comparison to other areas of the world? We saw at the end of Section 3 that colexification of 'bone' with 'strong' or with the related meaning 'hard' was, whilst rare, by no means exclusive to Melanesia. Sporadically in European languages, we find bone-hard/strong collocations like those discussed for Melanesian languages in Section 4.4., for instance, German knochenhart bone-hard 'very hard, very tough' and Russian krepk-oj kost-i hard-F.GEN.SG boneGEN.SG 'physically strong, sturdy' (cf. English rock-hard 'very hard' where the association is with rocks not bones). In many Semitic languages, 'bone' shares a single triconsonantal root with a range of meanings related to strength, a relationship that likely goes back to Proto-Semitic (Kogan and Militarev 2003: 293): Amharic ațənt 'bone' and ațəntam 'bony, robust, strong-boned'; Tigre Sáșəm 'bone' and Soșșum 'strong'; Arabic $\left\{a d^{\uparrow} m\right.$ 'bone' and $\left\{a d^{\uparrow} i: m\right.$ 'be great, powerful, important, awful'; Hebrew Secem 'bone', Socma 'power', Sacum 'huge', and hefecim 'empower' (among others). It is reasonable to assume that the association of Hittite haštāi 'bone' with 'strength' (Kloekhorst 2008: 325) is the result of contact with Semitic. Nonetheless, I am yet to find a similar concentration of linguistic expressions of the association in such a large number of language families over such a wide geographic region as in Linguistic Melanesia. 


\section{Conclusion}

In this paper I have argued that there is a widespread association between bone and strength in the Melanesian Linguistic Area. The striking areality of the BONES ARE STRENGTH association is readily missed in automatized approaches to lexical semantic typology and crude applications of the colexification methodology. Because in most languages there are not straightforward instances of colexification at the level of simplex lexemes, the complex expressions and idioms observed are unlikely to show up in word lists. There has been a recent surge in studies that make use of lexical databases, often not built for the purpose, in order to detect lexical patterns of interest to areal linguistics. As interesting as those studies are in their findings, and as useful as those databases are proving, this paper has illustrated the limitations of simplistic applications of the colexification approach and highlighted the necessity of careful investigation of typological patterns in the lexicon that go beyond the simple lexeme as a unit of analysis and that seek out contextualizing attestations to show recurrent semantic relationships in the data.

The colexification approach was meant to sidestep some of the most persistent complications for comparison of lexical semantics that had been raised and to provide a functionally grounded approach to comparison of meaning. In this paper, I have argued that by just looking at lexemes for 'bone' in isolation, we cannot observe pertinent morphosyntactic differences, let alone capture the shared similarities present in the Melanesian language data. It was shown that languages are scattered along a lexical-to-clausal cline in their expression of the lexico-semantic association of bone and strength, not to mention the large number of languagespecific idioms based on the association. Future work in developing the colexification approach, particularly its automatized implementations, will need to work to incorporate multi-morphemic and poly-lexical data in order to enhance the robustness of its results. Including figurative language in all its complexity, as witnessed by the BONES ARE STRENGTH association discussed here, will be particularly essential, since such complex linguistic structures are expected to accumulate more culturally significant information than simple structures. And it is the crosslinguistic study of these aspects of the lexicon encapsulating cultural variation that are most valuable for the discovery of areal skewings in linguistic patterns.

\section{Abbreviations}

1 first person

2 second person

3 third person 


$\begin{array}{ll}\text { ACT } & \text { active } \\ \text { ADJ } & \text { adjective } \\ \text { ADV } & \text { adverbial } \\ \text { ART } & \text { article } \\ \text { AUX } & \text { auxiliary } \\ \text { BAS } & \text { basic cross-referencing } \\ \text { CTR } & \text { controller } \\ \text { DECL } & \text { declarative } \\ \text { DEM } & \text { demonstrative } \\ \text { DER } & \text { derivational } \\ \text { EMPH } & \text { emphatic } \\ \text { F } & \text { feminine } \\ \text { FOC } & \text { focus } \\ \text { FPST } & \text { far past } \\ \text { IMP } & \text { imperative } \\ \text { INTR } & \text { intransitive } \\ \text { LOC } & \text { locative } \\ \text { M } & \text { masculine } \\ \text { NEG } & \text { negative } \\ \text { PL } & \text { plural } \\ \text { POSS } & \text { possessive } \\ \text { PRS } & \text { present tense } \\ \text { PST } & \text { past tense } \\ \text { REDUP } & \text { reduplication } \\ \text { SIM } & \text { similative } \\ \text { SG } & \text { singular } \\ \text { SS } & \text { switch subject } \\ \text { STAT } & \text { stative } \\ \text { TAM } & \text { tense, aspect, mood marking } \\ \text { VT } & \text { versatile tense } \\ & \end{array}$

\section{References}

Aikhenvald, Alexandra. 2008. The Manambu language of East Sepik, Papua New Guinea. Oxford: Oxford University Press.

Aiton, Grant. 2016. A grammar of Eibela: A language of the Western Province, Papua New Guinea. James Cook University PhD dissertation.

Andersen, Elaine. 1978. Lexical universals of body-part terminology. In Joseph H. Greenberg (ed.), Universals of human language, 335-368. Stanford: Stanford University Press.

Berlin, Brent \& Paul Kay. 1969. Basic color terms: Their universality and evolution. Berkeley, CA: University of California Press.

Bloomfield, Leonard. 1933. Language. [Revised from 1914 edition]. New York: Holt.

Bowden, Ross. 1997. A dictionary of Kwoma: A Papuan language of North-East New Guinea. Canberra: Pacific Linguistics. 
Burenhult, Niclas, C. Hill Juliette Huber, K. Rybka Saskia van Putten \& Lila San Roque. 2017. Forests: The cross-linguistic perspective. Geographica Helvetica 72. 455-464.

Deibler, Ellis W., Jr. 2008. Dictionaries of Alekano-English and English-Alekano. Ukarumpa: Summer Institute of Linguistics. Available at: http://www-01.sil.org/pacific/png/pubs/ 928474531283/Alekano_dict_a4.pdf.

Dobrovol'skij, Dmitrij \& Elisabeth Piirainen. 2010. Idioms: Motivation and etymology. In Annelies Häcki Buhofer (ed.), Yearbook of Phraseology, vol. 1, 73-96. Berlin: De Gruyter.

Donohue, Mark \& Bronwen Whiting. 2011. Quantifying areality: A study of prenasalisation in Southeast Asia and New Guinea. Linguistic Typology 15. 101-121.

Enfield, Nick \& Anna Wierzbicka. 2002. The body in description of emotion. Amsterdam: John Benjamins.

Evans, Nicholas \& David Wilkins. 2000. In the mind's ear: The semantic extensions of perception verbs in Australian languages. Language 76(3). 546-592.

Fillmore, Charles J., Paul Kay \& Mary Catherine O'Connor. 1988. Regularity and idiomaticity in grammatical constructions: The case of let alone. Language 64(3). 501-538.

Foley, W.A. 1986. The Papuan languages of New Guinea. Cambridge: Cambridge University Press.

François, Alexandre. 2008. Semantic maps and the typology of colexification: Intertwining polysemous networks across languages. In Martine Vanhove (ed.), From polysemy to semantic change: Towards a typology of lexical semantic associations, 163-215. Amsterdam: Benjamins.

François, Alexandre. 2020. Online Mwotlap-English-French dictionary. Electronic files. Paris: CNRS. Available at: http://tiny.cc/Mwotlap-dict.

Gast, Volker \& Maria Koptjevskaja-Tamm. 2018. The areal factor in lexical typology. In Daniël Olmen, Tanja Mortelmans \& Brisard Frank (eds.), Aspects of linguistic variation, 43-82. Berlin: De Gruyter Mouton.

Haspelmath, Martin. 2003. The geometry of grammatical meaning: Semantic maps and crosslinguistic comparison. In Michael Tomasello (ed.), The new psychology of language, vol. 2, 211-243. New York: Erlbaum.

Haspelmath, Martin \& Tadmor, Uri (eds.). 2009. World loanword database. Leipzig: Max Planck Institute for Evolutionary Anthropology. Available at: https://wold.clld.org/.

Heine, Bernd. 1997. Possession: Cognitive sources, forces, and grammaticalization. Cambridge: Cambridge University Press.

Jackson, Joshua Conrad, Joseph Watts, Teague R. Henry, List Johann-Mattis, Robert Forkel, Peter J. Mucha, Simon J. Greenhill, Russell D. Gray \& Kristen A. Lindquist. 2019. Emotion semantics show both cultural variation and universal structure. Science 366(6472). 1517-1522.

Key, Mary Ritchie \& Comrie, Bernard (eds.). 2015. The intercontinental dictionary series. Leipzig: Max Planck Institute for Evolutionary Anthropology. Available at: https://ids.clld.org/.

Kloekhorst, Alwin. 2008. Etymological dictionary of the Hittite inherited lexicon. Leiden: Brill. Kogan, Militarev, L.E. Kogan \& Alexander Militarev. 2003. Studia Semitica, Orientalia III. Moscow: Russian State University for the Humanities.

Koptjevskaja-Tamm, Maria (ed.). 2015. The linguistics of temperature. Amsterdam/Philadelphia: John Benjamins.

Koptjevskaja-Tamm, Maria \& Henrik Liljegren. 2017. Semantic patterns from an areal perspective. In Raymond Hickey (ed.), The Cambridge handbook of areal linguistics, 204-236. Cambridge: Cambridge University Press. 
Koptjevskaja-Tamm, Maria \& Martine Vanhove (eds.). 2012. New directions in lexical typology. [special issue]. Linguistics 50. 3.

Kulick, Don. 1992. Language shift and cultural reproduction: Socialization, self, and syncretism in a Papua New Guinea village. Cambridge: Cambridge University Press.

Lawes, William George. 1896. Grammar and vocabulary of language spoken by Motu tribe (New Guinea). Sydney: Goverment Printer.

Lawrence, Marshall. 2006. Oksapmin dictionary. Unpublished manuscript. Available at: https:// pnglanguages.sil.org/resources/archives/31137.

Laycock, Don. 1982. Linguistic diversity in Melanesia: A tentative explanation. In Rainer Carle, Martina Heinschke, Peter W. Pink, Christel Rost \& Karen Stadtlander (eds.), Gava': Studies in Austronesian languages and cultures dedicated to Hans Kähler, 31-37. Berlin: Reimer.

Laycock, Don. 2003. A dictionary of Buin, a language of Bougainville. Canberra: Pacific Linguistics.

Lichtenberk, Frantisek. 1991. Semantic change and heterosemy in grammaticalization. Language 67(3). 475-509.

List Johann-Mattis, Greenhill Simon, Anderson Cormac, Mayer Thomas, Tresoldi Tiago \& Forkel, Robert (eds.). 2018. Database of cross-linguistic colexifications. Jena: Max Planck Institute for the Science of Human History. Available at: http://clics.clld.org.

List Johann-Mattis, Thomas Mayer, Anselm Terhalle \& Matthias Urban. 2014. CLICS: Database of cross-linguistic colexifications. Marburg: Forschungszentrum Deutscher Sprachatlas. Available at: http://CLICS.lingpy.org.

McConvell, Patrick \& Maia Ponsonnet. 2013. Review of "Results and prospects in the study of semantic change: A review of From polysemy to semantic change (2008)". Journal of Language Contact 6(1). 180-196.

Mihalic, Francis. 1971. The Jacaranda dictionary and grammar of Melanesian Pidgin. Queensland: The Jacaranda Press, Milton.

Nozawa, Michiyo. 2006. Mende triglot dictionary. Ukarumpa: Summer Institute of Linguistics.

Östling, Robert. 2016. Studying colexification through massively parallel corpora. In Päivi Juvonen \& Maria Koptjevskaja-Tamm (eds.), The lexical typology of semantic shifts, 157-176. Berlin and Boston: De Gruyter Mouton.

Pericliev, Vladimir. 2015. On colexification among basic vocabulary. Journal of Universal Language 16(2). 63-93.

Ross, Malcolm. 1996. Contact-induced change and the comparative method: Cases from Papua New Guinea. In Mark Durie \& Malcolm Ross (eds.), The comparative method reviewed: regularity and irregularity in language change, 180-217. New York: Oxford University Press.

Ross, Malcolm. 1998. Possessive-like attribute constructions in the Oceanic languages of Northwest Melanesia. Oceanic Linguistics 37(2). 234-276.

Ross, Malcolm. 2001. Contact-induced change in Oceanic languages in North-West Melanesia. In Alexandra Y. Aikhenvald \& R.M.W. Dixon (eds.), Areal diffusion and genetic inheritance: Problems in comparative linguistics, 134-166. Oxford: Oxford University Press.

Ross, Malcolm. 2007. Calquing and metatypy. Journal of Language Contact 1. 116-143.

Ross, Malcolm. 2017. Languages of the New Guinea region. In Raymond Hickey (ed.), The Cambridge handbook of areal linguistics, 758-820. Cambridge: Cambridge University Press.

Rzymski, Christoph \& Tiago Tresoldi. 2020. The database of cross-linguistic colexifications, reproducible analysis of cross- linguistic polysemies. Scientific Data 13. https://doi.org/10. 1038/s41597-019-0341-x.

Sahlins, Marshall. 1963. Poor man, rich man, big man, chief: Political types in Melanesia and Polynesia. Comparative Studies in Society and History 5(3). 285-303. 
Schapper, Antoinette. 2017. Substratum inference through lexical patterns: A case study from Sunda-Sahul. Presented at Workshop on language shift and substratum interference in (pre) history, 11-12 July. Jena: MPI-SHH.

Schapper, Antoinette. 2019. The ethno-linguistic relationship between smelling and kissing: A Southeast Asian case study. Oceanic Linguistics 58(1). 92-109.

Schapper, Antoinette. 2020. Linguistic Melanesia. In Yaron Matras \& Evangelia Adamou (eds.), Routledge handbook of language contact, 480-502. London: Routledge.

Schapper, Antoinette \& Lourens de Vries. 2018. Comparatives in Melanesia: Concentric circles of convergence. Linguistic Typology 22(3). 437-494.

Schapper, Antoinette, Lila San Roque \& Rachel Hendery. 2016. Tree, firewood and fire in the languages of Sahul. In Maria Koptjevskaja-Tamm \& Päivi Juvonen (eds.), Lexico-typological approaches to semantic shifts and motivation patterns in the lexicon, 355-422. Berlin: Mouton de Gruyter.

Stebbins, Tonya N. \& Julius Tayul. 2012. Mali (Baining) dictionary. Canberra: Asia-Pacific Linguistics.

Talmy, Leonard. 1985. Lexicalization patterns. In Timothy Shopen (ed.), Language typology and synchronic description, vol. 3, 57-149. Cambridge: Cambridge University Press.

Thurston, William R. 1987. Processes of change in the languages of north-western New Britain. Canberra: Pacific Linguistics.

Thurston, William R. 1989. How exoteric languages build a lexicon: Esoterogeny in West New Britain. In Ray Harlow \& Robin Hooper (eds.), VICAL 1, Oceanic Languages: Papers from the Fifth International Conference on Austronesian Linguistics, 555-579. Auckland: Auckland: Linguistic Society of New Zealand.

Urban, Matthias. 2009. 'Sun' and 'moon' in the Circum-Pacific language area. Anthropological Linguistics 51. 328-346.

Urban, Matthias. 2010. 'Sun' = 'Eye of the Day': A linguistic pattern of Southeast Asia and Oceania. Oceanic Linguistics 49. 568-579.

Urban, Matthias. 2012. Analyzability and semantic associations in referring expressions. A study in comparative lexicology. PhD Dissertation, Leiden University.

van den Heuvel, Wilco. 2016. Aghu: Annotated texts with grammatical introduction and vocabulary lists. Canberra: Asia-Pacific Linguistics.

Vanhove, Martine (ed.). 2008. From polysemy to semantic change. Amsterdam, Philadelphia: John Benjamins.

Viberg, Ake. 1984. The verbs of perception: A typological study. In Brian Butterworth, Comrie Bernard \& Östen Dahl (eds.), Explanations for language universals, 123-162. Berlin: Mouton.

Wichmann Søren, Eric W. Holman \& Cecil H. Brown (eds.). 2018. The ASJP Database (version 18). Available at: https://asjp.clld.org/.

Zalizniak, Anna A., Maria Bulakh, Dmitrij Ganenkov, Ilya Gruntov, Timur Maisak \& Maxim Russo. 2012. The catalogue of semantic shifts as a database for lexical semantic typology.

Linguistics 50(3). 633-669.

Supplementary Material: The online version of this article offers supplementary material (https:// doi.org/10.1515/lingty-2021-2082). 